\title{
Reliability, validity, and factorial structure of the World Health Organization-5 Well-Being Index (WHO-5) in Iranian psychiatric outpatients
}

\author{
Confiabilidade, validade e estrutura fatorial do World Health Organization-5 \\ Well-Being Index (WHO-5) em pacientes psiquiátricos ambulatoriais iranianos
}

Mahboubeh Dadfar, ${ }^{1}$ Nahid Momeni Safarabad, ${ }^{2}$ Ali Asghar Asgharnejad Farid, ${ }^{2}$

Monir Nemati Shirzy, ${ }^{3}$ Farzad Ghazie pour Abarghouie ${ }^{2}$

\begin{abstract}
Introduction: The association between psychological well-being and physical and mental health has been shown in the literature. Psychological well-being is a multifaceted concept. The World Health Organization-5 Well-Being Index (WHO-5) is a 5-item instrument used to screen for depression. However, the validity of the WHO-5 has not been investigated in Iranian psychiatric or psychological settings.

Objective: To investigate the validation of the Farsi version of the WHO-5 in a sample of Iranian psychiatric outpatients.

Methods: A cross-sectional study was conducted with a convenience sample of 116 Iranian volunteer psychiatric outpatients selected from the psychiatric and psychological clinics at the School of Behavioral Sciences and Mental Health - Tehran Institute of Psychiatry, Iran University of Medical Sciences. Patients completed the WHO-5, the Patient Health Questionnaire-9 (PHQ9), the Patient Health Questionnaire-15 (PHQ-15), and the short form of the Beck Depression Inventory-13 (BDI-13).

Results: The mean score of the WHO-5 was 8.95 (standard deviation $[S D]=5.49)$. Cronbach's a for the WHO-5 was 0.91 . The WHO-5 negatively correlated with PHQ-9 (-0.358), PHQ$15(-0.328)$, and BDI-13 (-0.475), indicating good validity. Factor analysis of the WHO-5 items identified one factor labeled psychological well-being.

Conclusions: The WHO- 5 has a single dimensional structure and acceptable psychometric parameters. The results of this study suggest that WHO-5 can be used in a clinical context in Iran.

Keywords: Psychological well-being, validity, reliability, factorial structure, WHO-5, psychiatric outpatients, Iran.
\end{abstract}

\section{Resumo}

Introdução: A associação entre bem-estar psicológico e saúde física e mental tem sido demonstrada na literatura. Bemestar psicológico é um conceito multifacetado. O World Health Organization-5 Well-Being Index (WHO-5) é um instrumento composto por 5 itens utilizado para avaliar depressão. No entanto, a validade do WHO-5 não foi investigada em contextos psiquiátricos ou psicológicos iranianos.

Objetivo: Investigar a validade da versão persa do WHO-5 em uma amostra de pacientes psiquiátricos ambulatoriais iranianos. Métodos: Um estudo transversal foi conduzido com uma amostra de conveniência composta por 116 pacientes psiquiátricos ambulatoriais iranianos voluntários selecionados nas clínicas psiquiátrica e psicológica da School of Behavioral Sciences and Mental Health, Tehran Institute of Psychiatry, Iran University of Medical Sciences. Os pacientes completaram o WHO-5, o Patient Health Questionnaire-9 (PHQ-9), o Patient Health Questionnaire-15 (PHQ-15) e a versão abreviada do Beck Depression Inventory-13 (BDI-13).

Resultados: O escore médio obtido no WHO- 5 foi de 8,95 (desvio padrão $=5,49$ ). O alfa de Cronbach para o WHO-5 foi 0,91 . O WHO-5 se correlacionaram negativamente com o PHQ-9 $(-0,358)$, o PHQ-15 $(-0,328)$ e o BDI-13 $(-0,475)$, indicando validade adequada. A análise fatorial dos itens do WHO-5 identificaram um único fator, a saber, bem-estar psicológico.

Conclusão: O WHO-5 tem uma estrutura dimensional única e parâmetros psicométricos aceitáveis. Os resultados deste estudo sugerem que o WHO-5 pode ser usado em contextos clínicos no Irã.

Descritores: Bem-estar psicológico, validade, confiabilidade, estrutura fatorial, WHO-5, pacientes psiquiátricos ambulatoriais, Irã.

\footnotetext{
${ }^{1}$ School of Behavioral Sciences and Mental Health - Tehran Institute of Psychiatry, International Campus, School of Public Health, Iran University of Medical Sciences, Tehran, Iran. ${ }^{2}$ School of Behavioral Sciences and Mental Health - Tehran Institute of Psychiatry, Iran University of Medical Sciences, Tehran, Iran. ${ }^{3}$ Department of Psychology, West Tehran Branch, Islamic Azad University, Tehran, Iran.

Submitted Apr 13 2017, accepted for publication Jul 212017.

Suggested citation: Dadfar M, Momeni Safarabad N, Asgharnejad Farid AA, Nemati Shirzy M, Ghazie pour Abarghouie F. Reliability, validity, and factorial structure of the World Health Organization-5 Well-Being Index (WHO-5) in Iranian psychiatric outpatients. Trends Psychiatry Psychother. 2018;40(2):79-84. http://dx.doi.org/10.1590/2237-6089-2017-0044
} 
WHO-5, reliability, validity, and factorial structure in Iran - Dadfar et al.

\section{Introduction}

Well-being is a multifaceted, dynamic, complicated construct. There are many different studies of key dimensions of well-being. ${ }^{1}$ Well-being has components of psychological well-being/subjective well-being and emotional well-being. ${ }^{2,3}$

Psychological well-being and emotional well-being concepts were developed by researchers in the field of positive psychology, health psychology, organizational psychology and organizational behavior. Psychological wellbeing assesses well-being and it correlates with physical health. It refers to how people evaluate their personal and social life (i.e., internal experience and their perception of life) ${ }^{4-7}$ Emotional well-being, in turn, is necessary to the individual's health as a whole. It has been correlated with mental health issues ${ }^{8,9}$ and related to facets or Ryff's six domains of psychological well-being. ${ }^{10,11}$

The World Health Organization-5 Well-Being Index (WHO-5) can be used as a tool when screening for depressive symptoms, monitoring emotional well-being and psychological well-being, ${ }^{12-17}$ and also to assess the severity of suicide attempts. ${ }^{18,19}$

The validity of the WHO-5 has not been so far investigated in Iranian psychiatric and psychological settings. We examined psychometric and screening parameters for psychological well-being of this index in a sample of Iranian psychiatric outpatients.

\section{Methods}

A convenience sample of 116 Iranian volunteer psychiatric outpatients was selected from the psychiatric and psychological clinics at one site in Tehran, Iran, namely, the School of Behavioral Sciences and Mental Health - Tehran Institute of Psychiatry, affiliated with the Iran University of Medical Sciences. The patients were invited to voluntarily participate in the study after completing a psychiatric interview with one psychiatrist. Patients who agreed to participate provided written consent. The study protocol was approved by an institutional review board.

The patients completed the Farsi versions of the WHO-5, the Patient Health Questionnaire-9 (PHQ-9), the Patient Health Questionnaire-15 (PHQ-15), and the short form of the Beck Depression Inventory-13 (BDI-13).

\section{World Health Organization-5 Well-Being Index (WHO-5)}

The five items of the WHO-5 are associated with positive mood, vitality, and general interests; each of the items is rated on a 6-point Likert scale. Previous studies have reported acceptable psychometric parameters of the WHO-5 in different versions and in various clinical and non-clinical samples. ${ }^{15,20-27}$ The Farsi version of the WHO-5 was available at the WHO website in $2017 .{ }^{28}$

\section{Patient Health Questionnaire-9 (PHQ-9)}

The PHQ-9 is a tool designed for the assessment of depression. It contains nine items focusing on the past two weeks; each item is scored using a 4-point Likert scale ranging from 0 to 3 . Previous studies have shown good psychometric characteristics for the PHQ-9.21,29-38

\section{Patient Health Questionnaire-15 (PHQ-15)}

The PHQ-15 is a short, self-reported instrument used to screen for somatoform symptoms. It covers 15 somatic symptoms and focuses on the past four weeks. Each symptom is scored from 0 to 2 . Studies have indicated high internal consistency and acceptable validity for the PHQ-15.37 For example, the PHQ-15 correlated with the Patient Health Questionnaire-2 (PHQ-2) at 0.45.27

\section{Short form of the Beck Depression Inventory-13 (BDI-13)}

The BDI-13 is a screening instrument for depressive symptoms. Good psychometric properties have been reported, and three factors identified, for the BDI-13. ${ }^{39}$ The BDI-13 correlated with the PHQ-2 at 0.69. ${ }^{27}$

\section{Results}

The mean age of the patients was 35.48 years (standard deviation $[S D]=12.20$ ). Mean duration of psychiatric disorder was 5.61 years $(S D=5.16)$. In the total sample, $81.8 \%$ were female; $48.1 \%$ were single, $46.3 \%$ married, $4.6 \%$ divorced, and $0.9 \%$ widowed. The majority had 12 years of education (59.7\%), and $40.4 \%$ had a bachelor's degree (BA) and higher degree. With regard to mental health diagnoses, $22.5 \%$ had an anxiety disorder, $70 \%$ a depressive disorder, and $7.5 \%$ had other disorders.

The mean score of the WHO-5 was $8.95(S D=5.49)$. The lowest mean score obtained was $1.58(\mathrm{SD}=1.33)$ for item 4, and the highest mean score was 2.03 $(S D=1.20)$ for item 1 (Table 1$)$.

In the present study, the mean scores of the other tools were calculated, and resulted as follows: $\mathrm{PHQ}-9$, $12.83(\mathrm{SD}=6.25)$; PHQ-15, $10.46(\mathrm{SD}=5.70)$; and BDI$13,9.65(\mathrm{SD}=5.92)$. 


\section{Reliability coefficients of the WHO-5}

Cronbach's a for the WHO-5 was 0.91, indicating high internal consistency. For the other questionnaires, Cronbach's a values were as follows: PHQ-9, 0.88; PHQ-15, 0.85; and BDI-13, 0.80.

\section{Inter-item and item-total correlations in the WHO-5}

The correlations between items and the total score of the WHO-5 were high, ranging from 0.79 to 0.90 . The correlations between items ranged from 0.54 for items 3 and 5, to 0.75 for items 4 and 5, denoting moderate correlation (Table 2).

\section{Correlations between WHO-5 and other questionnaires}

Table 3 shows the correlations between the WHO-5 and other measures, demonstrating moderate validity and association between the instruments (Table 3 ).

\section{Factor analysis of the WHO-5}

The Kaiser-Meyer-Olkin measure of sampling adequacy (KMO) was 0.874, indicating sample adequacy; Bartlett's test of sphericity was 377.330 $(d f=10, p<0.001)$, suggesting that factor analysis was justified in the sample. The results of the exploratory factor analysis on the WHO-5 found only one factor.

Table 1 - Scores obtained for each WHO-5 item and total score

\begin{tabular}{lcccc}
\hline WHO-5 & Minimum & Maximum & Mean & SD \\
\hline 1. Being cheerful and good spirits & 0.00 & 5.00 & 2.03 & 1.20 \\
2. Being calm and relaxed & 0.00 & 5.00 & 2.02 & 1.29 \\
3. Being active and vigorous & 0.00 & 5.00 & 1.66 & 1.22 \\
4. Waking up fresh and rested & 0.00 & 5.00 & 1.58 & 1.33 \\
5. Being interested in things & 0.00 & 5.00 & 1.64 & 1.33 \\
Total score & 0.00 & 25.00 & 8.95 & 5.49 \\
\hline
\end{tabular}

SD = standard deviation; WHO-5 = World Health Organization- 5 Well-Being Index.

Table 2 - Pearson's inter-item and item-total correlations ( $r$ )

\begin{tabular}{lcccccc}
\hline Items & $\mathbf{1}$ & $\mathbf{2}$ & $\mathbf{3}$ & $\mathbf{4}$ & $\mathbf{5}$ & Total \\
\hline 1 & 1 & & & & & \\
2 & $0.736^{*}$ & 1 & & & & \\
3 & $0.570^{*}$ & $0.617^{*}$ & 1 & & & \\
4 & $0.679 *$ & $0.742^{*}$ & $0.679 *$ & 1 & & \\
5 & $0.650 *$ & $0.715^{*}$ & $0.547^{*}$ & $0.754 *$ & 1 & \\
Total & $0.844^{*}$ & $0.890^{*}$ & $0.792^{*}$ & $0.902 *$ & $0.860 *$ & 1 \\
\hline
\end{tabular}

* Significant at 0.01 level.

Table 3 - Pearson's correlations ( $r$ ) between the questionnaires

\begin{tabular}{lc}
\hline Questionnaires & r with WHO-5 \\
\hline The PHQ-9 & $-0.358^{*}$ \\
The PHQ-15 & $-0.328^{+}$ \\
The BDI-13 & $-0.475^{+}$ \\
\hline
\end{tabular}

BDI-13 = Beck Depression Inventory-13; PHQ-9 = Patient Health Questionnaire-9; PHQ-15 = Patient Health Questionnaire-15; WHO-5 = World Health Organization-5 Well-Being Index.

* Significant at the 0.05 level.

+ Significant at the 0.01 level. 
WHO-5, reliability, validity, and factorial structure in Iran - Dadfar et al.

Factor 1 ( 5 items) explained $73.67 \%$ of the variance and was labeled psychological well-being (Table 4 and Figure 1).

\section{Discussion}

The aim of the study was to investigate psychometric parameters for depression of the WHO-5 in an Iranian clinical sample.

The mean score of the WHO-5 was 8.95 ( $S D=5.49)$, denoting poor psychological well-being in the sample. A study by Khosravi et al. ${ }^{25}$ reported a mean WHO- 5 score of $13.4(\mathrm{SD}=6.5)$ in an Iranian sample. In another study, the Thai version of the WHO-5 showed a mean score of $14.32(S D=5.26)$ in primary care patients. ${ }^{24}$
Cronbach's a for the WHO-5 was 0.91, indicating good reliability. Other studies have shown good Cronbach's a values for the WHO-5.1,16,20,21,24-26,40-45

Inter-item correlations were significant for items 3 and 5, and also for items 4 and 5. The associations between the items and the WHO-5 total score were significant for items 3, 4, and the total score.

In our study, the WHO-5 negatively correlated with the other measures assessed, denoting good validity. Findings of Khosravi et al. ${ }^{25}$ and Mortazavi et al. ${ }^{26}$ showed that the WHO-5 negatively correlated with the 28-item General Health Questionnaire (GHQ$28 ; r=-0.66$ and $r=-0.64$, respectively). The study by Blom et al. ${ }^{45}$ found that the WHO-5 negatively correlated with the Beck Depression Inventory (BDI$6 ; r=-0.49)$. Guðmundsdóttir et al. ${ }^{40}$ reported that the

Table 4 - Factor loadings of the WHO-5 in Iranian psychiatric outpatients

\begin{tabular}{lc}
\hline WHO-5 Items & Component \\
\hline Over the last two weeks: & \\
1. I have felt cheerful and in good spirits. & 0.84 \\
2. I have felt calm and relaxed. & 0.89 \\
3. I have felt active and vigorous. & 0.78 \\
4. I woke up feeling fresh and rested. & 0.90 \\
5. My daily life has been filled with things that interest me. & 0.85 \\
Eigenvalue & 3.68 \\
$\%$ of Variance & 73.67 \\
\hline
\end{tabular}

WHO-5 $=$ World Health Organization-5 Well-Being Index.

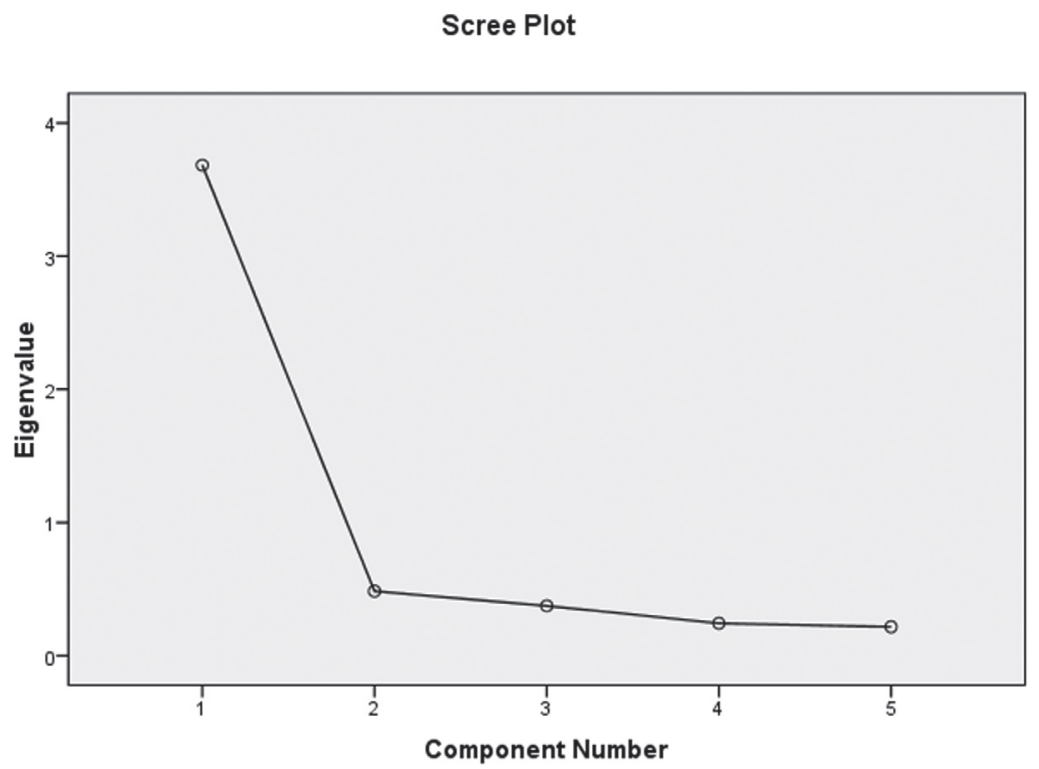

Figure 1 - Scree plot for the World Health Organization-5 Well-Being Index (WHO-5). 
WHO-5 negatively correlated with other inventories of depression and anxiety. $\mathrm{Wu}^{21}$ and Saipanish et al. ${ }^{24}$ found that the WHO-5 negatively correlated with the Hospital Anxiety and Depression Scale (HADS-Depression; -0.54 and -0.57 , respectively). Also, $\mathrm{Wu}^{21}$ indicated that the WHO-5 positively correlated with the World Health Organization Quality of Life (WHOQOL) and negatively associated with the PHQ-9 in patients with metabolic syndrome.

We identified one factor, labeled psychological wellbeing, which accounted for $73.67 \%$ of the variance. Our finding is similar to previous studies that also obtained a single factor. 2,21,24,25,38 It seems that the 1-factor solution represents the best fit for the WHO-5.

\section{Conclusions}

The validation process of the Farsi version of the WHO-5 showed psychometric parameters consistent with those reported in previous studies, suggesting that it measures concepts that are similar to those measured by the original version. The WHO-5 has a single dimensional structure and acceptable psychometric parameters.

The results of this study suggest that the WHO- 5 can be used in a clinical context in Iran. The use of distinct cut-off points for different purposes and populations, Rasch's item response theory (IRT) approaches, and receiver operating characteristic curve (ROC) for depression or more severe mental disorders, are all suggested.

\section{Disclosure}

No conflicts of interest declared concerning the publication of this article.

\section{References}

1. Linton MJ, Dieppe P, Medina-Lara A. Review of 99 selfreport measures for assessing well-being in adults: exploring dimensions of well-being and developments over time. BMJ Open. 2016;6:010641.

2. Bech P. Measuring the dimensions of psychological general wellbeing by the WHO-5. QoL Newsletter. 2004;32:15-6.

3. Bech $P$, Olsen LR, Kjoller M, Rasmussen N. Measuring well-being rather than the absence of distress symptoms: A comparison of the SF-36 mental health subscale and the WHO-Five well-being scale. Int J Methods Psychiatr Res. 2003;12:85-91.

4. Ryff CD. Happiness is everything, or is it? Explorations on the meaning of psychological well-being. J Pers Soc Psychol. 1989;57:1069-81.

5. Winefield HR, Gill TK, Taylor AW, Pilkington RM. Psychological well-being and psychological distress: Is it necessary to measure both? Psychol Well-Being Theo Res Pract. 2012;2:1-16.
6. Fernandes T, Sanyal N, Dhupar S. Perceived social support, affect and psychological well-being in married and widowed older adults. Int J Indian Psychol. 2016;3:48-60.

7. Ashkanasy NM, Dorris AD. Emotion in workplace. Ann Rev Org Psychol Org Behav. 2017;4:67-90.

8. Şimşek ÖF. An intentional model of emotional well-being: The development and initial validation of a measure of subjective well-being. J Happiness Stud. 2011;12:421-2.

9. Australian Institute of Health and Welfare. Social and emotional wellbeing: development of a Children's Headline Indicator. Canberra: AIHW; 2012. Cat. no. PHE 158.

10. Ryff C, Keyes C. The structure of psychological well-being revisited. J Pers Soc Psychol. 1995;69:719-27.

11. Schütte S, Chastang JF, Malard L, Parent-Thirion A, Vermeylen G, Niedhammer I. Psychosocial working conditions and psychological well-being among employees in 34 European countries. Int Arch Occup Environ Health. 2014;87:897-907.

12. Schneider $C B$, Pilhatsch $M$, Rifati $M$, Jost $W H$, Wodarz $F$, Ebersbach $\mathrm{G}$, et al. Utility of the WHO-Five Well-being Index as a screening tool for depression in Parkinson's disease. Mov Disord. 2010;25:777-83.

13. Papanas N, Tsapas A, Papatheodorou K, Papazoglou D, Bekiari $E$, Sariganni $M$, et al. Glycaemic control is correlated with wellbeing index (WHO-5) in subjects with type 2 diabetes. Exp Clin Endocrinol Diabetes. 2010;118:364-7.

14. Lucas-Carrasco $R$, Allerup $\mathrm{P}$, Bech $\mathrm{P}$. The validity of the WHO-5 as an early screening for apathy in an elderly population. Cur Gerontol Geriatr Res. 2012;2012:171857.

15. Furuya M, Hayashino Y, Tsujii S, Ishii H, Fukuhara S. Comparative validity of the WHO-5 Well-Being Index and two-question instrument for screening depressive symptoms in patients with type 2 diabetes. Acta Diabetol. 2013;50:117-21.

16. Allgaier AK, Kramer D, Saravo B, Mergl R, Fejtkova S, Hegerl U. Beside the Geriatric Depression Scale: the WHO-Five Well-being Index as a valid screening tool for depression in nursing homes. Int J Geriatr Psychiatry. 2013;28:1197-204.

17. Krieger T, Zimmermann J, Huffziger S, Ubl B, Diener C, Kuehner $C$, et al. Measuring depression with a well-being index: further evidence for the validity of the WHO Well-Being Index (WHO5) as a measure of the severity of depression. J Affect Disord. 2014;156:240-4.

18. Sisask M, Värnik A, Kõlves K, Konstabel K, Wasserman D. Subjective psychological well-being (WHO-5) in assessment of the severity of suicide attempt. Nord J Psychiatry. 2008;62:4315 .

19. Awata S, Bech P, Yoshida S, Hirai M, Suzuki S, Yamashita M, et al. Reliability and validity of the Japanese version of the World Health Organization-Five Well-Being Index in the context of detecting depression in diabetic patients. Psychiatry Clin Neurosci. 2007;61:112-9.

20. Topp CW, Østergaard SD, Søndergaard S, Bech P. The WHO-5 WellBeing Index: a systematic review of the literature. Psychother Psychosom. 2015;84:167-76.

21. Wu SFV. Rapid screening of psychological well-being of patients with chronic illness: Reliability and validity test on WHO-5 and PHQ-9 scales. Dep Res Treat. 2014;2014:239490.

22. de Wit M, Pouwer F, Gemke RJ, Delemarre-van de Waal HA, Snoek FJ. Validation of the WHO-5 well-being index in adolescents with type 1 diabetes. Diabetes Care. 2007;30:2003-6.

23. Hajos TR, Pouwer F, Skovlund SE, Den Oudsten BL, GeelhoedDuijvestijn $\mathrm{PH}$, Tack $\mathrm{CJ}$, et al. Psychometric and screening properties of the WHO-5 well-being index in adult outpatients with type 1 or type 2 diabetes mellitus. Diabet Med. 2013;30:63-9.

24. Saipanish $R$, Lotrakul M, Sumrithe $S$. Reliability and validity of the Thai version of the WHO-Five Well-Being Index in primary care patients. Psychiatry Clin Neurosci. 2009;63:141-6.

25. Khosravi A, Mousavi SA, Chaman R, Sepidar Kish M, Ashrafi E, Khalili $M$, et al. Reliability and validity of the Persian version of the World Health Organization-Five well-being index. Int J Health Stud. 2015;1:17-9.

26. Mortazavi $F$, Mousavi SA, Chaman $R$, Khosravi A Validation of the World Health Organization-5 well-being index; assessment of maternal well-being and its associated factors. Turk Psikiyatri Derg. 2015;26:48-55.

27. Dadfar M, Lester D. Psychometric characteristics of Patient Health Questionnaire-2 (PHQ-2) in Iranian psychiatric outpatients. Austin J Psychiatry Behav Sci. 2017;4:1059.

28. World Health Organization. The WHO-5-Region Hovedstadend Psykiatri. Hillerød: Psychiatric Research Unit, Mental Health Centre North Zealand; 2017. 
WHO-5, reliability, validity, and factorial structure in Iran - Dadfar et al.

29. Johnson JG, Harris ES, Spitzer RL, Williams JBW. The Patient Health Questionnaire for Adolescents: Validation of an instrument for the assessment of mental disorders among adolescent primary care patients. J Adolesc Health. 2013;30:196-204.

30. Neves I, Sales C, Carlota R, Brinquete C, Magalhães A, Falcão C, et al. Relevance of individualized measures: Listening the patient means capturing the story? Psicol Saude Doencas. 2016;17:3944.

31. Torres A, Monteiro S, Pereira A, Albuquerque E. Reliability and validity of the PHQ- 9 in Portuguese women with breast cancer. EpSBS. 2016;7:411-23.

32. Inagaki $\mathrm{M}$, Ohtsuki $\mathrm{T}$, Yonemoto $\mathrm{N}$, Kawashima $\mathrm{Y}$, Saitoh $\mathrm{A}$, Oikawa Y, et al. Validity of the Patient Health Questionnaire (PHQ)-9 and PHQ-2 in general internal medicine primary care at a Japanese rural hospital: a cross-sectional study. Gen Hosp Psychiatry. 2013;35:592-7.

33. Santos I, Tavares BF, Munhoz TN, Almeida LSPD, Silva NTBD, Tams BD, et al. Sensitivity and specificity of the Patient Health Questionnaire-9 (PHQ-9) among adults from the general population. Cad Saude Publica. 2013;29:1533-43.

34. Rathore JS, Jehi LE, Fan Y, Patel SI, Foldvary-Schaefer N, Ramirez $\mathrm{MJ}$, et al. Validation of the Patient Health Questionnaire-9 (PHQ-9) for depression screening in adults with epilepsy. Epilepsy Behav. 2014;37:215-20.

35. Zhong Q, Gelaye B, Fann JR, Sanchez SE, Williams MA. Crosscultural validity of the Spanish version of PHQ-9 among pregnant Peruvian women: a Rasch item response theory analysis. J Affect Disord. 2014;158:148-53.

36. Hanwella R, Ekanayake S, De Silva VA. The validity and reliability of the Sinhala translation of the Patient Health Questionnaire (PHQ9) and PHQ-2 screener. Dep Res Treat. 2014;2014:768978.

37. Xiong N, Fritzsche K, Wei J, Hong X, Leonhart R, Zhao X, et al. Validation of Patient Health Questionnaire (PHO) for major depression in Chinese outpatients with multiple somatic symptoms: a multicenter cross-sectional study. J Affect Disord. $2015 ; 174: 636-43$
38. Van der Zwaam GL, Van Dijk SE, Adriaanse MC, Van Marwijk HW, Van Tulder MW, Pols AD, et al. Diagnostic accuracy of the Patient Health Questionnaire- 9 for assessment of depression in type II diabetes mellitus and/or coronary heart disease in primary care. J Affect Disord. 2016;15:68-74.

39. Dadfar M, Kalibatseva Z. Psychometric properties of the Persian of the short Beck Depression Inventory (BDI-13) with Iranian psychiatric outpatients. Scientifica. 2016;2016: 8196463.

40. Guðmundsdóttir HB, Olason DP, Guðmundsdóttir DG, Sigurðsson JF. A psychometric evaluation of the Icelandic version of the WHO-5. Scand J Psychol. 2014;55:567-72.

41. Allgaier AK, Pietsch K, Frühe B, Prast E, Sigl-Glöckner J, SchulteKörne G. Depression in pediatric care: is the WHO-Five Well-Being Index a valid screening instrument for children and adolescents? Gen Hosp Psychiatry. 2012;34:234-41.

42. Sibai AM, Chaaya M, Tohme RA, Mahfoud $Z$, Al-Amin $H$. Validation of the Arabic version of the 5-item WHO Well Being Index in elderly population. Int J Geriatr Psychiatry. 2009;24:106-7.

43. Awata $S$, Bech $P$, Koizumi, $Y$, Seki, T, Kuriyama, S, Hozawa Ohmori $\mathrm{K}$, et al. Validity and utility of the Japanese version of the WHOFive Well-Being Index in the context of detecting suicidal ideation in elderly community residents. Int Psychogeriatr. 2007;19:7788.

44. Bonsignore $M$, Barkow $K$, Jessen $F$, Heun R. Validity of the FiveItem WHO Well-Being Index (WHO-5) in an elderly population. Eur Arch Psychiatry Clin Neurosci. 2001;251:27-31.

45. Blom EH, Bech P, Högberg G, Larsson JO, Serlachius E. Screening for depressed mood in an adolescent psychiatric context by brief self-assessment scales--testing psychometric validity of WHO5 and BDI-6 indices by latent trait analyses. Health Qual Life Outcomes. 2012;10:149.

\section{Correspondence:}

Nahid Momeni Safarabad

E-mail: nahidmomeni57@gmail.com 